diera decirnos "lo que realmente pensó..." o el escepticismo claudicante de quien piense que toda reconstrucción es ya una falsificación, creo que podemos asumir con confianza una posición que quisiera calificar de 'sensata': la buena historia de la filosofía no es la que viene empaquetada y etiquetada de tal o cual manera (minuciosa, doxográfica, analítica, dialéctica, estética, etc.), sino sencillamente aquella que, por combinar virtudes estéticas, análisis minuciosos y una perspectiva determinada, echa luz sobre el pensamiento de los pensadores en cuestión de un modo particular y nos facilita por ello el que sigamos adelante en nuestra propia investigación.

\title{
RELEVANCIA DE LA HISTORIA DE LA FILOSOFİA PARA LA FILOSOFÍA
}

Elia Nathan

Instituto de Investigaciones Filosóficas, UNAM

Comencemos por destacar ciertos hechos. En todo departamento de filosofía siempre hay cursos en que se estudia el pensamiento de filósofos del pasado, y estos cursos históricos son tan importantes como los cursos de filosofía contemporánea. Este fenómeno parece estar íntimamente relacionado con el tipo de actividad intelectual que realizan los filósofos profesionales. En efecto, es frecuente que aun los filósofos originales o innovativos utilicen ciertas teorías filosóficas del pasado para el desarrollo de su propio pensamiento; así, Husserl desarrolla unas meditaciones "cartesianas", Heidegger alude sistemáticamente a concepciones griegas, etc. Dados estos hechos, debemos preguntarnos qué papel desempeña esta referencia no gratuita a las filosofías del pasado para el desarrollo de una filosofía presente o actual. Conviene aclarar aquí que no queremos afirmar que toda filosofía presente necesariamente se remite a un pasado, sino que sólo sostenemos que algunas teorías filosóficas se remiten explícitamente a una teoría pasada, pero basta esta posibilidad de remitirse al pasado para que nos cuestionemos sobre el porqué de dicha referencia por parte de algunas filosofías actuales.

Esta pregunta cobra mayor importancia si recordamos que no toda empresa teórica guarda la misma relación con su pasado que la que guarda la filosofía. En efecto, notoriamente en el caso de las ciencias naturales, las teorías propuestas en el pasado lejano son 
absolutamente irrelevantes para el desarrollo de las teorías actuales. Así, por ejemplo, los físicos contemporáneos nunca utilizan ideas de los atomistas griegos, más aún, ni siquiera estudian la física clásica tal y como fue desarrollada por Galileo o Newton, los químicos no piensan que encontrarán ideas valiosas en la teoría del flogisto, etc. Por ello mismo, a los estudiantes de cualquier ciencia natural rara vez se les enseña la historia de esa ciencia, y si se lo hace, esta materia es considerada como secundaria. Así, cabe preguntarse por qué algunos quehaceres teóricos, como la filosofía, guardan una estrecha relación con su pasado, mientras que otros, como las ciencias naturales, no lo hacen.

La respuesta a esta pregunta parecería consistir en que las filosofías del pasado desempeñan dos papeles: a) pueden fungir como fuentes de ideas que serán desarrolladas o criticadas por filosofías actuales, o bien b) pueden utilizarse como criterios para determinar qué cuenta como un pensamiento filosófico aceptable en el presente.

Examinemos este segundo punto con más cuidado. Si consideramos globalmente a la filosofía desde la antigüedad a nuestros días, puede verse que ella tiene dos características. Por una parte, no tiene un objeto de estudio específico ya que, en principio, cualquier objeto o tema puede ser estudiado filosóficamente. Por otra parte, tampoco tiene una única metodología, sino que, como podemos constatar a través de toda la historia de la filosofía, ésta se ha caracterizado por una gran diversidad de enfoques. Ahora bien, esta enorme diversidad temática y metodológica de la filosofía genera el problema de determinar qué puede contar como pensamiento filosófico y qué no. Pienso que la manera como se determina es apelando a los filósofos clásicos del pasado, o sea, apelando a aquellas teorías o doctrinas que la tradición ha llegado a reconocer como filosofías. En verdad, ésta es la razón por la cual se dan cursos de historia de la filosofía: dada la ausencia de criterios claros y especificables respecto de qué temas y metodologías son filosóficos, el estudiante aprende a pensar filosóficamente a través del estudio de los filósofos clásicos, que fungen como modelos o paradigmas de pensamientos filosóficos. Dicho en otras palabras, las filosofías del pasado cumplen una función normativa con respecto a las filosofías actuales: ellas son la autoridad que determina, por lo menos parcialmente, qué puede ser considerado como un pensamiento filosófico.

El comparar a la filosofía con las ciencias naturales puede aclarar este punto. Ciertamente para las ciencias naturales contemporáneas las teorías científicas del pasado no desempeñan ningún papel normativo, o sea, no pueden ser utilizadas para determinar qué cuenta como una teoría científica legítima, ya que las ciencias naturales han 
alcanzado un grado de desarrollo tal, que ya no está en duda ni cuál es su objeto de estudio, ni cuál su metodología. Ahora bien, debido a que las ciencias naturales cuentan con "criterios" intracientíficos para la aceptabilidad de teorías, como el de la metodología experimental, no se ven obligadas a recurrir a teorías del pasado como fuentes de autoridad. Por otra parte y a diferencia de lo que ocurre en las ciencias naturales, en el caso de la filosofía la base empírica es sumamente pobre y difusa - basta recordar que el dato del que generalmente parten los análisis epistemológicos es "sabe que p", o "todos los cuervos son negros", etc., en algunas filosofías de la ciencia. Esta pobreza de la base empírica en el caso de la filosofía se compensa por el hecho de que las teorías se justifican con base en los dictados de la razón o requisitos intelectuales. Empero, la "razón" es tan amplia y variada que no basta para determinar como correcta o verdadera a una teoría filosófica frente a otras; más aún, ni siquiera basta para determinar un único enfoque como filosófico -así, tan racional o intelectualmente aceptable es la filosofía de Santo Tomás como la de Nietzsche. Es precisamente por ello, por fundarse en la razón o intelecto, y por carecer de una base empírica bien definida, por lo que la filosofía recurre a su pasado como fuente de autoridad.

Hemos visto así que uno de los papeles que desempeña la historia de la filosofía es un papel normativo consistente en determinar qué cuenta como filosófico y qué no; también sostuvimos que esta función se cumple principalmente durante el entrenamiento de los estudiantes de filosofía. Veamos ahora la segunda función que desempeñan las filosofías del pasado en relación con las actuales. Como dijimos antes, esta función consiste en que las filosofías pasadas pueden ser fuente de ideas a ser desarrolladas o criticadas por los filósofos del presente durante la elaboración de su propio pensamiento. Esto es algo bien sabido, así que no abundaré más en ello aquí. Lo único que quisiera destacar es que también en este caso las filosofías del pasado cumplen una función de autoridad. En verdad, lo que las filosofías del pasado ofrecen no son meramente ideas, sino ideas legítimas o prestigiosas. Esto resulta claro si imaginamos un texto filosófico en que frecuentemente se haga referencia a las ideas del filósofo mexicano del siglo XVI, Alonso de la Veracruz; ciertamente este texto tendrá muy poca credibilidad, aun suponiendo que logre captar nuestro interés. En cambio, un texto en que se afirma desarrollar, digamos, una epistemología de corte kantiano, merecerá nuestro respeto aun cuando estemos en desacuerdo con las ideas allí expresadas. Y nos lo merecerá porque las comunidades filosóficas de distintas épocas y culturas han considerado que la epistemología kantiana es una teoría o bien verdadera o bien que contiene intui- 
ciones valiosas. En otras palabras, ciertas filosofías del pasado son fuente de ideas con prestigio porque la historia las ha valorado como filosofías viables o plausibles, o sea, porque ha habido un consenso por parte de varias culturas en distintas épocas históricas respecto de la verdad o plausibilidad de esas filosofías.

Tal y como hemos desarrollado el tema, parecería que afirmamos que la filosofía es una empresa intelectual tradicionalista, es decir, una empresa en que lo pasado es considerado como lo más valioso y, por ende, como algo que debe ser considerado como la autoridad. Pero la situación no es tan desesperada. Ciertamente, como hemos querido mostrar, la filosofía es una empresa tradicionalista o conservadora, pero también es una empresa en la que hay lugar para la creatividad, la originalidad, la innovación. En efecto, la otra gran fuente de autoridad para la filosofía es la razón. La razón (individual) es capaz de crear nuevas ideas, nuevas metodologías, nuevos criterios filosóficos, etc., que las comunidades filosóficas y culturales pueden llegar a aceptar como legítimos y valiosos.

Empero, ¿son dos fuentes independientes de autoridad la tradición y la razón?, o sea, ¿la razón sólo aporta nuevas ideas, enfoques, etc., sin ser capaz de interactuar con la tradición filosófica? Pienso que la razón también es capaz de leer creativamente a las filosofías del pasado. Más aún, pienso que las filosofías del presente que pretenden aportar algo y no ser meramente comentarios, utilizan las ideas de alguna filosofía del pasado de una manera creativa, o sea, la razón concibe dichas ideas bajo una nueva luz, o las desarrolla de distinta manera de como fueron desarrolladas en el pasado, etc.; en pocas palabras, la razón las reinterpreta para que resulten significativas en el presente, además de que ofrece argumentos en favor de su verdad. Es importante destacar aquí que si bien las filosofías del pasado son fuente de ideas prestigiosas, son sólo fuente de prestigio y no de verdad; en efecto, para que las ideas del pasado puedan aceptarse como verdaderas en la actualidad, deben ser probadas como tales. Así, si bien la tradición filosófica es una autoridad para el presente, es una autoridad sui generis, ya que requiere ser reinterpretada $y$ justificada para poder decir algo aceptable para el presente.

Para terminar, quisiera examinar algunas de las consecuencias que tienen las ideas anteriormente expuestas para la metodología de la historia de la filosofía. Pienso que la tradición filosófica puede aprehenderse de dos maneras distintas. Una de ellas es cuando, con el fin de desarrollar una teoría filosófica, se apela a la tradición como fuente de ideas que tienen autoridad o son prestigiosas. En este caso, la filosofía del pasado es reinterpretada ya que sólo así es posible que una serie de ideas que fueron significativas para un contexto cultural 
pasado, y que ya no es vigente actualmente, puedan llegar a tener sentido dentro del contexto cultural del presente. Por ello, cuando un filósofo del presente "hace historia", cuando afirma, por ejemplo, que Descartes descubrió al sujeto cognoscente como conciencia, casi siempre hace una historia mítica, una historia que no pretende ser demasiado fiel al pasado, pero que sí busca ante todo encontrar aquellas ideas que son significativas para el presente. En cambio, en la otra manera de aprehender la tradición filosófica, y que se puede clasificar estrictamente como historia o historiografía de la filosofia, el objetivo principal es conocer el pasado. En este caso, el criterio fundamental es el de cualquier historiografía: la fidelidad al pasado, o sea, el intento de describir y explicar un evento pasado objetivamente, dentro de su muy específico contexto histórico.

Ahora bien, describir y explicar objetivamente un pensamiento filosófico del pasado significa en parte captar el sentido que dicho pensamiento tenía para el autor y sus contemporáneos, es decir, significa captar el sentido que tenía dentro de la cultura específica en que fue generado. Para lograr esto es fundamental que el historiador no imponga ni los valores ni las creencias básicas de su cultura a los sistemas filosóficos del pasado, sino que trate de comprender un pensamiento filosófico pasado en términos de los valores y creencias básicas de la cultura en la que se gestó. Así, por ejemplo, un historiador de la modernidad al examinar la tesis dualista alma-cuerpo no debe preguntarse si esta tesis es verdadera o falsa, o si está o no bien fundamentada por tal o cual filósofo moderno, ya que no le corresponde contestar estas preguntas qua historiador (aunque sí $q u a$ filósofo), sino que ha de preguntarse cómo y por qué esta tesis fue tan debatida en el siglo XVII. Para contestar esto deberá tomar en cuenta el contexto cultural dentro del que se dio dicho debate, contexto que incluye una cultura no secularizada como la nuestra y la aparición por primera vez de una concepción mecanicista de la naturaleza, aspectos no presentes en nuestra cultura y que deben tenerse en cuenta al evaluar la importancia y el atractivo que en su momento tuvieron los sistemas filosóficos que estudia el historiador. Un historiador que no tomase en cuenta la íntima conexión de la tesis dualista con una comprensión cristiana de la realidad, no sólo estaría imponiendo su concepción de la realidad a un sistema de pensamiento pasado, y por lo que no sería una descripción objetiva del pasado, sino que tampoco sería capaz de explicar por qué fue exitoso dicho sistema de pensamiento (en este caso, por qué fue un tema clave la cuestión del dualismo en el siglo XVII).

$\mathrm{Si}$ bien estas ideas son muy pobres como.guías metodológicas, pienso que sí nos permiten catalogar como ilegítimo cierto tipo de 
textos filosóficos bastante frecuentes, textos pretendidamente de historia de la filosofía, pero en los cuales encontramos, junto con la presentación de las ideas de un autor del pasado, desarrollos originales de estas ideas por parte del historiador-filósofo. Lo que me parece ilegítimo de esta mezcla de filosofía e historia es que lleva a que ni se satisfagan criterios filosóficos de verdad, ni criterios históricos de veracidad u objetividad. En efecto, lo que usualmente sucede en este tipo de textos híbridos es que se considera que no hay que dar razones para probar la verdad de la idea o teoría desarrollada, ya que se está haciendo historia, pero precisamente esta falta de argumentación es la que da lugar a que la filosofía allí desarrollada sea mala filosofía; por otra parte, tampoco se considera que importe demasiado la falta de fidelidad histórica, ya que se le llega dar más interés al desarrollo de cierta idea o teoría del autor pasado que se estudia, falta de fidelidad que hace que la historiografía presentada en dichos textos híbridos sea una mala historia.

\section{FILOSOFÍA E HISTORIA DE LA FILOSOFÍA}

MaURicio Beuchot

Instituto de Investigaciones Filosóficas, UNAM

Las preguntas que orientan el siguiente trabajo son dos: (i) ¿Cuál es la importancia de la historia de la filosofía para hacer filosofía? $y$, en el supuesto de que la historia de la filosofía sea útil para hacer filosofía, (ii) ¿cuál es un buen método para hacer dicha historia de la filosofía? ${ }^{9}$

Frente a las polémicas acerca de si tenemos que acercarnos más a la recuperación del pasado o inclinarnos más a la comunicación del pasado de una manera relevante para los lectores del presente, me parece que una buena aportación metodológica nos la brinda la conjunción de hermenéutica y teoría de la argumentación. La hermenéutica nos enseña que siempre se introduce nuestra subjetividad cultural en la historia que leemos o que escribimos; por ello nuestra actitud historiográfica tiene limitaciones, y hay que dar un mayor énfasis al diálogo interpretativo con los filósofos de la historia pasada. Además, veo que en el diálogo con los autores del pasado vale lo que ocurre en el dialogo con los actuales: hay condiciones para

9 Sobre las posibles relaciones de la filosofía y la historia de la filosofía, cfr. J. J. E. Gracia, "La filosofía y su historia", en Revista Latinoamericana de Filosofía, 13 (1987), pp. 259-278. 